\section{Apple Micrografting Protocol to Establish Transgenic Clones on Field Ready Rootstock}

\author{
W. David Lane, ${ }^{1}$ \\ Basdeo Bhagwat, ${ }^{2}$ \\ John D. Armstrong, ${ }^{3}$ \\ and Susan Wahlgren ${ }^{2}$
}

Additional IndeX wORDs. tissue culture, shoot culture, shoot tip, Malus domestica, 'M.9'

\begin{abstract}
Summary. A protocol for micrografting shoot tips harvested from in vitro shoot cultures directly to transplanted rootstock plants in the greenhouse was developed. Shoot tips of the apple (Malus domestica) cultivars Golden Delicious, Granny Smith and Fuji clone, Nagafu12, were harvested, stored in a water bath then prepared for grafting by cutting the stem immediately below the tip into a wedge shape leaving the tip approximately 3 $\mathrm{mm}(0.12 \mathrm{inch})$ long. The rootstock cultivar, Malling 9 (M.9) (M. domestica), was prepared by cutting into a young fast growing side branch to expose the cambium, creating a pocket into which the shoot tip was inserted. The cut section of the tip was oriented so as to contact the exposed rootstock cambium and was held in place by wrapping with a strip of pliable plastic film. Two weeks later the wrapping was loosened and the grafted branch cut back. Side branches of the rootstock were not removed until later in order to support rootstock growth. The scion shoots developed into nursery whips suitable for transplanting to a screen house or field after 2 months. The protocol proved to be a simple
\end{abstract}

PARC contribution 2201. We thank Michael Weiss for the photography. This research was supported by an AAFC, Matching Investment Initiatives, grant awarded to W.D.L. and the collaborating partner Okanagan Biotechnology Inc.

1,2 Pacific Agri-Food Research Centre, Agriculture and Agri-Food Canada, Summerland, B.C., VOH 1Z0, Canada.

${ }^{3}$ Okanagan Biotechnology Inc., P.O. Box 1533, Summerland, B.C., V0H 1Z0, Canada.

${ }^{1}$ To whom reprint requests should be addressed. E-mail address: LaneWD@agr.gc.ca. efficient way to rapidly grow nursery trees from tissue culture clones developed in genetic modification experiments and was used to propagate several hundred plants. Grafting success was often $100 \%$ but was reduced if quality of shoot tips was poor due to injury indicated by brown tip color. The protocol eliminates the steps of rooting, acclimatizing and growing shoots into plants to serve as a scion wood source.

\section{A} pple is the most important temperate fruit tree crop. Conventional hybridization has resulted in several new and commercially important cultivars but improvement has been hampered by it's perennial nature and long generation time. Apple plants are large, thereby constraining the number of hybrids that can be screened, and seedlings are slow to come into bearing due to its juvenile phase. Fruiting can be advanced by grafting scions onto a dwarfing rootstock that induces precocious bearing (Barritt et al., 1990; Lewandowski and Zurawicz, 2000). An alternative method to advance the bearing of hybrids, transgenic, and other clones of special interest is to extending the growing season using continuous greenhouse culture as described by Yao et al. (1999). Many apple cultivars have undergone clonal selection where naturally occurring mutations for improved fruit quality or tree growth characteristics have been evaluated and the best clones propagated vegetatively for commercial use (Ferree and Schmid, 2001).

Directed clonal improvement is an attractive alternative to hybridization, or selection and evaluation of spontaneous mutations since, at least for some traits, improvements to commercially established clones may be possible using molecular genetic techniques and the changes are targeted and matched to crop improvement goals. Some examples of transgenic traits in vegetatively propagated crops are development of potato (Solanum tuberosum) clones with silenced polyphenol oxidase (Bachem et al., 1994; Coetzer et al., 2001), virus resistance in papaya (Carica papaya) (Ferreira et al., 2002) and apple clones expressing a Bacillus thuringiensis protein toxic to major apple pests (Dandekar et al., 2002). The first transformed apple clones were developed a decade ago (Bondt et al., 1994) and transforma- tion experiments have continued in a number of laboratories (Gittins et al., 2001; Holefors et al., 2000; Ko et al., 2002). Research is underway in our laboratory and others (Murata, et al., 2000) to develop transgenic apple clones with silenced polyphenol oxidase to facilitate development of fresh cut apple products and to reduce the impact of bruising on fruit quality and grades through silencing of the enzymatic browning reaction.

Apple cultivars are propagated commercially by using chip or $\mathrm{T}$ budding that are both side budding techniques based on fusing a bud excised from 1-year-old wood of the scion to the stem of a rootstock plant at the end of the rootstock liner's second year's growth. The rootstock is pruned immediately above the scion cultivar bud that develops into a nursery tree the following growing season. The nursery tree is harvested and transplanted to an orchard block the following spring and fruiting occurs 2 or 3 years later. Apple seedling plants that originate from hybridization, or rooted cuttings from in vitro cultures, are slower to produce fruit. Therefore, scion wood is harvested after seedlings reach 1 to $2 \mathrm{~m}$ (3.3 to $6.6 \mathrm{ft})$ in height and is grafted to a dwarfing rootstock to promote flowering.

Tissue culture propagation of apple using shoot cultures is a well-established laboratory procedure (Lane, 1978) but own-rooted tissue-culturederived plants of fruit cultivars are not used commercially because of the universal use of dwarfing rootstocks. Rootstocks are sometimes propagated in vitro, especially when there is a need to increase plant numbers of new cultivars in short supply, but the normal method is layer beds where developing shoots grow in soil mounded around them, develop roots in this environment and are then removed from the mother plant. The rooted plantlet is called a layer. Genetic transformation of apple depends on regeneration of shoots from leaf explants harvested from shoot cultures, and plants of transformed clones generated in vitro suffer from the same limitation of delayed bearing as own-rooted micropropagated tissue culture plantlets. An efficient micrografting protocol that resulted in clones established on a rootstock at an early growth stage would save the several months of time required for both rooting of tissue culture plantlets 
in vitro, and for growth and development of the rooted plantlets to a stage suitable for harvesting scion-wood for traditional grafting. The advantages of a micrografting protocol using shoot tips from in vitro cultures would be to reverse juvenility that possibly results from adaptation to growth in tissue culture, faster establishment of field plants and earlier fruiting because of the rootstock effect. Delays due to season, when rootstocks and nursery trees develop outside, could be avoided because the shoot culture scions are produced in the laboratory, and the rootstock plants maintained in a greenhouse, isolated from weather effects.

Micrografting is useful for other purposes including some applicable to apple. Some viruses can be eliminated by micrografting a meristem tip small and young enough that it does not include vascular tissue nor the viruses contained in this tissue (Faggiol et al., 1997; Hadidi, 1995). Micrografting has been used to screen transformed clones modified to silence virus replication by grafting them to shoot culture stocks that are infected with virus (Heuss et al., 1999). The virus does not transmit to or infect resistant micrografted scion clones. Micrografting can be used as a clonal propagation method for difficult to root but valuable specimens (Guo and Deng, 1998) and has been used to screen for graft compatibility and to study the physiology of the rootstock scion interaction of apple (Zhu et al., 1999). It has been used extensively in conifer (Pinophyta) and other tree tissue culture to induce juvenility in propagules derived from mature trees promoting establishment in tissue culture and rooting of selected mature trees that are otherwise recalcitrant (Arnaud et al., 1993; Ewald and Kretzschamer, 1996; Perrin et al., 1994; Ponsonby, and Mantell, 1993; Thimmappaiah et al., 2002). To achieve this, buds isolated from mature scion wood are micrografted to seedling rootstocks or tissue culture shoots in vitro.

This report describes an simple efficient protocol for micrografting apple shoot tips harvested from in vitro shoot cultures onto commercially available rootstock plants growing in pots in a greenhouse. We have used the protocol to save time in establishing transgenic clones as nursery trees on dwarfing rootstock resulting in quicker establishment of field trials and earlier fruit production. Micrografting avoids the step of rooting in vitro shoots then growing own rooted plants to provide a source of scion wood for use in grafting and traditional nursery tree development.

\section{Materials and methods}

Shoot tissue cultures. Shoot tissue cultures of the apple cultivars Golden Delicious, Granny Smith and Fuji, NagaFu 12 clone, were initiated from shoot tips collected from the Certified Budwood Orchard located at the Pacific Agri-Food Research Centre, Summerland, B.C. They were established as axenic shoot cultures growing on Murashige and Skoog (MS) medium following previously described methods (Lane, 1992). The maintenance medium contained the macro and micro elements and vitamins as described by Murashige and Skoog (1962) but the growth regulator benzyl amino purine at a concentration of $3.5 \mu \mathrm{M}$, and agar at a concentration of $7 \%$ were added. The medium was autoclaved and dispensed into $500-\mathrm{mL}$ (1 pint) glass jars. The cultures were transferred to fresh medium at 3-week intervals.

Plasmid construction. A vector for transformation experiments was constructed. It contained a partial sequence of an apple polyphenol oxidase gene, in antisense orientation, under the control of the double-enhanced cauliflower mosaic virus $35 \mathrm{~S}$ promoter and nopaline synthase terminator incorporated into the binary plant transformation vector $\mathrm{pBINPLUS \text {(Engelen }}$ et al., 1995). The vector pBINPLUS provides the selection marker gene, NptII, that results in resistance to kanamycin. The final vector, pGEN-II was electroporated into the Agrobacterium tumifaciensstrain EHA105 in preparation for plant transformation.

TRANSFORMATION PROTOCOL. Leaf explants from the shoot cultures were used in transformation experiments following published methods (Bondt et al., 1994). Young leaf explants were cut, perpendicular to the mid rib, into three or four strips. These were inoculated with the engineered Agrobacterium strain described above and co-cultivated for $4 \mathrm{~d}$ in the dark at $25^{\circ} \mathrm{C}(77.0$ $\left.{ }^{\circ} \mathrm{F}\right)$. At the end of this period they were thoroughly washed to remove Agrobacterium and incubated on regeneration medium containing an antibiotic to prevent Agrobacterium growth and the selective agent kanamycin at a concentration of $6 \mathrm{mg} \cdot \mathrm{L}^{-1}(\mathrm{ppm})$. The leaf strips were incubated 10 strips / petri plate containing regeneration medium. The regeneration medium consisted of MS medium containing the growth regulators TDZ [1-phenyl-3-( $1,2,3,-$ thiadiazol-5-yl) urea] at $23 \mu \mathrm{M}$, IBA (indolbutryric acid) at $1.3 \mu \mathrm{M}$ and $2-\mathrm{iP}$ [ $\mathrm{N}^{6}-(2$-isopentenyl) adenine $]$ at 10.5 $\mu \mathrm{M}$. Incubation was in the dark for 2 weeks at $25^{\circ} \mathrm{C}$, followed by 2 weeks in alternating light and dark with a period of $16: 8 \mathrm{~h}$ and $24^{\circ} \mathrm{C}\left(75.2^{\circ} \mathrm{F}\right)$. At the end of this period, regenerating explants were transferred to fresh medium for a further 4-week period then surviving cultures were transferred to shoot culture maintenance medium plus kanamycin at $60 \mathrm{mg} \cdot \mathrm{L}^{-1}$.

Characterization of clones as TRANSGENIC. Polymerase chain reaction (PCR), a method for amplifying a specific DNA fragment, was used to screen the genomic DNA of the putative transformed plants for the presence of the kanamycin-resistance (NptII) selection marker and the polyphenol oxidase transgene. Kanamycin-resistant lines shown by PCR to carry both the selection marker and the transgene were considered to be transgenic. Regeneration of shoots on selective medium containing $60 \mathrm{mg} \cdot \mathrm{L}^{-1}$ of kanamycin indicated the presence of the functional selection marker.

MicRografting MATERIALS: SHOOT CULTURES. Transgenic clones maintained as proliferating shoot cultures on maintenance medium were harvested for micrografting at the end of the 3 week growth period (Fig. 1A). Tips were aseptically excised from elongated shoots, 1 to $3 \mathrm{~cm}$ ( 0.6 to 1.8 inch) long and placed in water in a plastic container (Fig. 1B). In these experiments 6-10 shoots were harvested from each clone. They were then held at $4{ }^{\circ} \mathrm{C}\left(39.2^{\circ} \mathrm{F}\right)$ until used only for a period shorter than $24 \mathrm{~h}$. The cultures from which the tips were harvested were transferred to fresh medium and maintained in the normal way.

Micrografting MATERIALS: ROOTSTOck. Dormant liners of the apple rootstock cultivar M.9 were obtained in March from a local supplier. Their roots were trimmed leaving each about $4 \mathrm{~cm}$ (1.5 inch) long and they were potted into $20-\mathrm{L}(5.3$-gal) plastic pots containing potting mix. The mix was formulated by combining $107 \mathrm{~L}$ $(28.3 \mathrm{gal})$ of the peat based growing 


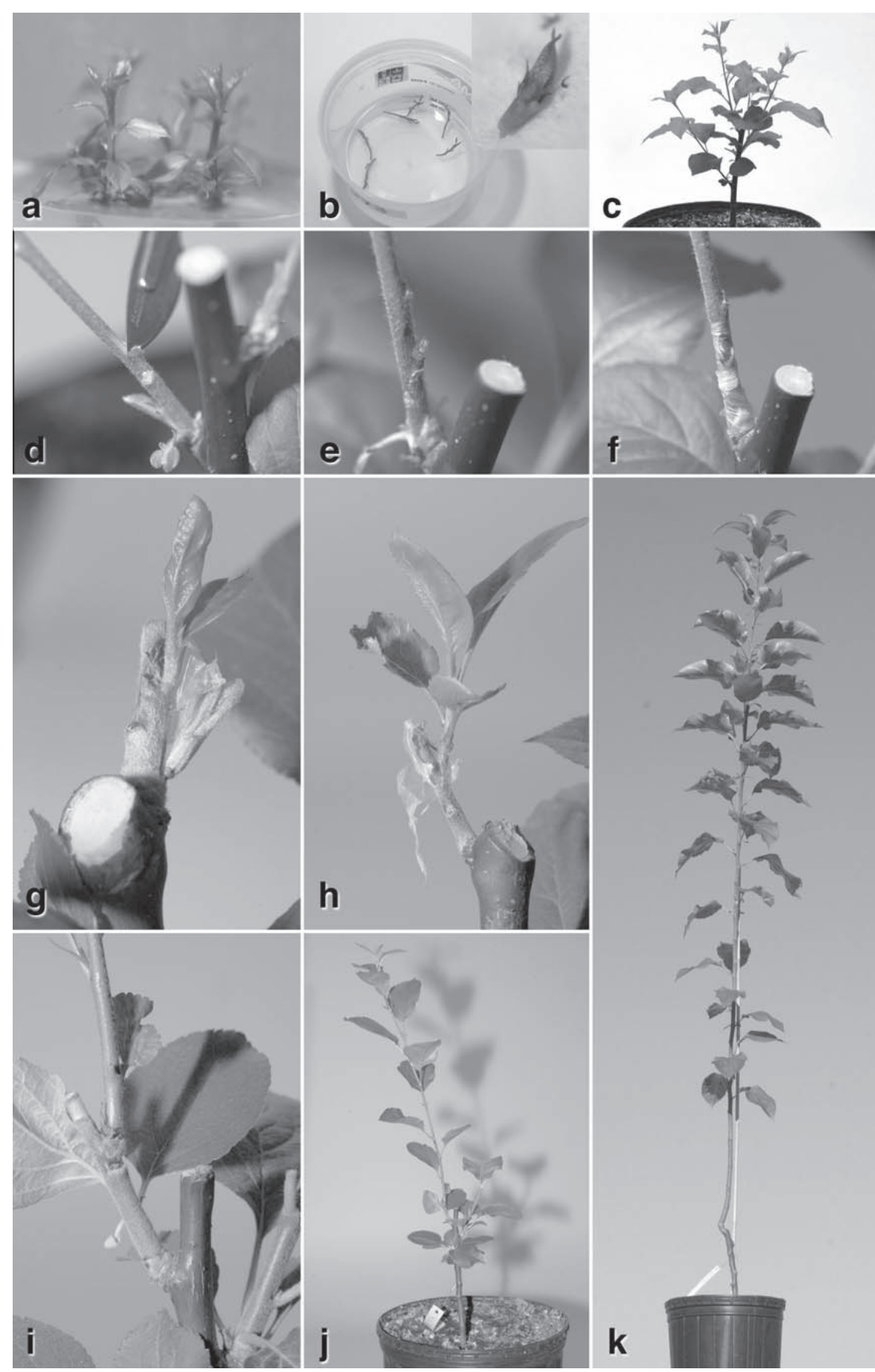

Fig. 1. (A) 'Golden Delicious' apple shoot cultures from which shoot tips for grafting were harvested. (B) Harvested shoot tips floating in water ; insert, the shoot tip prepared for grafting by cutting the stem into a wedge shape, length about 3 $\mathrm{mm}(0.1$ inch $)$. (C) The potted 'M.9' rootstock plant with side branches in suitable condition for grafting; the plant stem is about $1 \mathrm{~cm}(0.4 \mathrm{inch})$ in diameter. (D) Side branch of the rootstock cut to expose the cambium. (E) The scion shoot tip inserted in the rootstock oriented so the cambium of scion and rootstock are in contact. (F) The graft immobilized by wrapping with Parafilm. (G) Two weeks after grafting the side branch with the graft was cut back and the wrap cut to loosen it; 3 weeks after grafting the scion shoot has begun to develop; note that the appearance of the scion and rootstock are different. $(\mathrm{H})$ Four side branches are left on the rootstock to support the early growth of the scion shoot. (I) At 5 to 6 weeks after grafting the scion is developing rapidly and the remaining rootstock side branches are removed. (J) At 7 weeks the scion shoot benefits from support with a stake and can be moved to an outdoor location. (K) Three-month nursery tree developed from a micrograft about $2 \mathrm{~m}(6.6 \mathrm{ft})$ in height. mix Premier Pro-Mix BX (Premier Horticulture Inc., Red Hill, Pa.) plus $107 \mathrm{~L}$ of pine wood shavings and 450 $\mathrm{g}$ (1 lb) of 14-14-14 slow-release fertilizer (14N-6.2P-11.6K; Nutricote, Nichimen, Japan). One rootstock plant was placed in each pot then the stock was pruned to a length of $20 \mathrm{~cm}(7.9$ inch), the pot was placed in a greenhouse room maintained at approximately $20^{\circ} \mathrm{C}\left(68.0{ }^{\circ} \mathrm{F}\right)$ and watered with a solution of $5 \mathrm{~g} \cdot \mathrm{L}^{-1}(0.5 \%)$ of 10N-22.9P-8.3K (Plant-Prod, Plant Products Co. Ltd, Brampton, Ontario) fertilizer. Subsequently the plants were fertilized biweekly with a solution of $3 \mathrm{~g} \cdot \mathrm{L}^{-1}(0.3 \%) \quad 15 \mathrm{~N}-6.6 \mathrm{P}-14.9 \mathrm{~K}$ (Plant-Prod Soilless Mix Fertilizer). The rootstock plants broke dormancy and developed 5 to 10 shoots, 10 to $25 \mathrm{~cm}$ (3.9 to 9.8 inches) in length, after about 1 month in the greenhouse. The shoots were thinned leaving five per plant. Shoots were suitable for micrografting when they had reached $4 \mathrm{~cm}$ (1.6 inch) or more in length. The plants were sprayed to control powdery mildew, mites, thrips and aphids following standard methods recommended for greenhouse crops. Once shoots reached $40 \mathrm{~cm}$ (15.7 inches) in length they were cut back to a bud close to the rootstock trunk to initiate a fresh shoot. The shoots were cut back in sequence over a period of 2 to 3 weeks to achieve the purpose of maintaining a continuous supply of young rapidly growing shoots and to leave sufficient leaf area on the rootstock plant to maintain its good health and vigor.

Micrografting method. The micrografting protocol consisted of the following steps. 1) A work station was assembled on a lab cart with supplies consisting of about six to ten shoot culture tips of a transgenic clone in water in a plastic container (Fig. 1B) with about five clones prepared for grafting in each work session; forceps to remove the shoot from the water; a scalpel to prepare the shoot tip and rootstock for grafting; a platform for cutting the tip, usually a $250-\mathrm{mL}$ beaker inverted and covered with a damp paper towel; marker pen and labels to identify the rootstock scion combination; 1-cm-wide strips (0.4-inch) of Parafilm (American National Can, Menasha, Wis.) to wrap the grafted shoot tip immobilizing it in correct orientation to the rootstock.2) An upward oriented shoot that was actively growing and 5 
Table 1. A series of micro-grafting operations that illustrate the success rate of the protocol for grafting apple shoot tips from transgenic shoot culture clones to side branches of potted 'M.9' rootstock growing in a greenhouse.

\begin{tabular}{lccc}
\hline $\begin{array}{c}\text { Clone } \\
\text { no. }\end{array}$ & $\begin{array}{c}\text { Micrografts } \\
\text { (no.) }\end{array}$ & $\begin{array}{c}\text { Date } \\
\text { grafted }\end{array}$ & $\begin{array}{c}\text { Graft } \\
\text { development } \\
(\%)\end{array}$ \\
\hline 605 & 6 & 24 May & 83 \\
523 & 6 & 24 May & 67 \\
260 & 6 & 24 May & 67 \\
246 & 6 & 24 May & 100 \\
520 & 6 & 27 May & 83 \\
604 & 6 & 27 May & 50 \\
255 & 6 & 27 May & 100 \\
534 & 6 & 27 May & 67 \\
240 & 6 & 3 June & 83 \\
613 & 6 & 3 June & 67 \\
601 & 6 & 3 June & 83 \\
241 & 6 & 3 June & 50 \\
523 & 6 & 10 June & 50 \\
273 & 7 & 10 June & 72 \\
605 & 6 & 10 June & 83 \\
246 & 7 & 10 June & 100 \\
\hline
\end{tabular}

to $25 \mathrm{~cm}$ (2.0 to 9.8 inches) in length was selected (Fig. 1C). 3) An incision was made into the stock stem cutting through the cambium making a flap about $5 \mathrm{~mm}(0.2$ inch) long (Fig. 1D); a second cut initiated about $3 \mathrm{~mm}(0.1$ inch) up-stem from the first and parallel to it created space for the scion shoot tip and exposed a larger area of cambium than a single cut after the intervening strip of rootstock tissue was removed. 4 ) The shoot tip scion was then prepared by cutting the stem at an angle of about $30^{\circ}$ from the axis of the stem from opposite sides to create a wedge shaped end to the stem tip. The length of the prepared tip was 3 to $5 \mathrm{~mm}$. 5) It was then placed in the prepared rootstock branch and oriented so that the cambium, exposed by the cut, on one or both sides of the stem was in contact with the freshly cut wedge shaped base of the scion shoot tip. (Fig. 1E). 6) The scion was then held in place with several wraps of the Parafilm strips. The wrap began below the graft and enclosed the graft so as to prevent desiccation and push the scion and rootstock together so they would more completely fuse (Fig. IF). 7) On day 14, after grafting, the grafted rootstock branch was excised immediately above the graft and the other branches on the rootstock were pruned leaving 15 to $30 \mathrm{~cm}$ (5.9 to 11.8 inches) of each branch intact and the highest point of the pruned branches lower on the plant than the graft; and on day 21 the Parafilm wrap was cut, on the opposite side of the branch to the bud, to relieve pressure but was not removed from the graft. 8) At 3 to $10 \mathrm{~d}$ later the scion began to grow pushing free of the Parafilm (Fig. 1 G and H). 9) The scion continued to grow reaching a length of about $50 \mathrm{~cm}$ (19.7 inches) 8 weeks after grafting. (Fig. 1 I and J).10) At this time it was supported by tying to a stake and either allowed to continue growing in the greenhouse or transferred outside to a screen house that met standards for confinement (Fig. 1K).

\section{Results and discussion}

A previous report describes a method for micrografting using, as rootstock, apple seedlings at the cotyledon stage or slightly older, and shoot tips from cultures as the scion (Huang and Millikan, 1980) and similar procedures using shoot tip cultures as rootstock have been described by Obeidy and Smith (1991) and Dobranszki et al., (2000). In these procedures the micrografts were placed as an apical graft where the shoot tip of a stock plant seedling was excised and the scion immobilized in contact with the cut surface until fusion occured. Side grafting is another method, where the shoot tip of the stock plant is left intact and the scion grafted to a cleft in the side of a branch or stem (Monteuuis, 1995; Mukhopadhyay et al., 1997; Prakash et al., 1999). In preliminary experiments we investigated apical grafting of tips harvested from apple shoot cultures using germinated apple seed at the cotyledon stage as stock. We achieved some success but the procedure was cumbersome, took considerable dexterity and, in our hands, grafting success was inconsistent. Grafting onto young seedling stocks had the potential to by pass the in vitro rooting stage but did not achieve the purpose of establishing the clones on a dwarfing rootstock known to promote precocious bearing. The side graft protocol described here was used in our lab for 2 years and resulted in 250 transgenic clones established as nursery trees on the dwarfing rootstock, 'M.9' and successfully established in field trials. The nursery trees developed using this protocol seem similar or identical to field grown nursery trees and although we have not had extensive experience with their fruiting response, fruit bud development appears to follow the same pattern as comparable trees propagated using traditional methods.

The rate of success of the micrografting protocol is illustrated in a typical series of experiments described in Table 1. The overall success of those experiments averaged $93 \%$ but not all clones responded equally. A less than perfect response resulted from using shoot tips of poor quality for grafting. Poor quality clones had some degree of browning and were harvested from weak shoots growing at the base of the shoot culture cluster rather than from dominant shoots. The results illustrate that even when poor quality shoots were used, the micrografting protocol resulted in establishment of some plants on dwarfing rootstock. The cultivar of apple used did not strongly influence grafting success in our experiments, a result consistent with the experience in peach micrografting experiments $(\mathrm{He}$ uss et al., 1999). The time required for an experienced technician to do 30 micrografts was about $l \mathrm{~h}$. The time required to maintain 200 rootstocks in a greenhouse room was about $\mathrm{l} \mathrm{h} /$ week. The micrografting protocol had a considerable efficiency advantage when compared to the more common procedure of rooting shoots harvested from shoot cultures in vitro, acclimating the rooted plantlets in specialized conditions, establishing greenhouse plants of sufficient size to harvest budwood for grafting to rootstock, then grafting the rootstock, and allowing the bud to develop into a nursery tree.

Maintenance of RoOtstock. Individual rootstocks have been maintained in the greenhouse for a period of 1 year and young vigorous 
side branches in condition suitable for micrografting were sustained by cutting back branches to a bud close to the rootstock stem once they reached a length of $40 \mathrm{~cm}$ (15.7 inch). The rootstocks were trained to five branches and these were cut back in sequence, one or two at a time, at intervals of about one month in order to have a continuous supply of branches for micrografting on each stock. Rootstocks grew well when spaced on $30 \mathrm{~cm}$ ( 11.8 inch) centers and were maintained in healthy condition with no significant disease or pest problems.

SCION SHOOT TIP INFLUENCES. Ideal shoot tips were ones in active growth at the end of the shoot culture transfer interval but tips harvested from older cultures that had stopped elongation and formed a terminal bud were also successfully grafted provided they had not developed brown tissue. In both cases placement of the bud in the graft cleft and wrapping the graft was facilitated by excising large leaf blades. Shoot tips that were stored at $4{ }^{\circ} \mathrm{C}$ for periods longer than $24 \mathrm{~h}$ began to turn brown indicating injury or death and this made them unsuitable for grafting. The condition of the tips could be monitored by development of the brown color. A comparison of 3-5 $\mathrm{mm}$ tips with larger ones $1 \mathrm{~cm}$ long, indicated larger shoots were not advantageous. Fusion of the scion tip to the rootstock close to the meristem tip, rather than some distance down the scion stem, promoted grafting success and was more easily achieved with short shoot tips rather than longer ones. This may have resulted because the cut tissue nearer the tip consisted of smaller less differentiated cells that divided and fused to the stock more consistently.

The scion shoot tip was often smaller in diameter than the cut made in the stock so the two exposed cambium strips in the rootstock did not line up with the cambium in the scion shoot tip. Since fusion originates from division of cambium cells, the scion was oriented so it was touching one of the cambium strips of the stock and in most cases this proved sufficient to result in a successful graft union. This also allowed a greater size range of stock branch to be used.

THE DEVELOPING SCION. If the wrap immobilizing the graft was loosened 7 $\mathrm{d}$ after grafting some scions survived but success was less consistent than at
$14 \mathrm{~d}$, but delaying this procedure for an additional $7 \mathrm{~d}$ neither hindered or promoted grafting success. When the wrap was loosened early it was common for the shoot tip to brown and die but for the basal portion of the scion to remain alive. One or several axillary shoots from this basal portion of the scion sometimes developed but their emergence was inconsistent, their development into shoots was delayed and often they had weak shoot growth and development. Loosening the wrap rather than removing it entirely promoted consistent growth of the scion bud since acclimatization was achieved as the shoot emerged from the wrap. If the wrap was not cut, most buds were constrained and were not able to grow out of the wrap. Positioning the graft close to the main stem of the stock plant and orienting the graft so that the developing scion shoot grew directly upward resulted in a young nursery plant with a more or less straight stem, but since the scion shoot origin was from a branch rather than the stock main stem, where buds are traditionally placed, a characteristic crook developed in the stem of most micrografted plants (Fig. 1K).

One of the five branches on the rootstock was used for grafting. This density of branches and leaves was found to be suitable for maintaining good growth with all branches in active growth. The branches were left intact to support the growth of the developing scion but were prevented from competing with it by ensuring the developing scion shoot tip was uppermost and the dominant branch of the tree. If the supporting branches were removed when the scion tip was small, growth was dependent on reserves in the rootstock rather than photosyntate and resulted in a less consistent and slower rate of scion shoot growth. Once the developing scion shoot was well established, with approximately 20 leaves, the rootstock branches were removed. When there was urgency in establishing clones on dwarfing rootstocks, two grafts per rootstock plant increased the probability that every rootstock would have one successful graft. This micrografting procedure results in field ready trees in 10 to 12 weeks from grafting with the time being influenced by greenhouse conditions and the size of plant required. Establishing plants in the field is dependant on suitability of seasonal conditions for transplanting.
The micrografting protocol was quick and convenient and resulted in field ready trees on dwarfing rootstock more quickly than alternative, traditional tissue culture propagation procedures. Often clones of interest were identified at irregular intervals. Micrografting was well suited to processing these clones as they become available since the method is quick, easy and consistently successful providing suitable rootstocks were available. Few steps are required reducing complexity and promoting achievement of the goal.

\section{Literature cited}

Arnaud, Y., A. Franclet, H. Tranvan, and M. Jacques. 1993. Micropropagation and rejuvenation of Sequoia sempervirens: A review. Ann. Sci. For. (Paris). 50:273-295.

Bachem, C.W.B., G.J. Speckmann, P.C.G.van-der Linde, V.F.T. Merheggen, M.D. Hunt, J.C. Steffens, M. Zabeau, and P.C.G. Van-der-Linde. 1994. Antisense expression of polyphenol oxidase genes inhibits enzymatic browning in potato tubers. Biotechnology 12:1101-1105.

Barritt, B.H., M.A. Dilly, and B.J. Schonberg. 1990. New dwarfing rootstocks for high density plantings. Good Fruit Grower 41:5-8.

Bondt, A. de, K. Eggermont, P. Druart, M. de Vil, I. Goderis, J. Vanderleyden, and W. Broekaert. 1994. Agrobacterium-mediated transformation of apple (Malus $\times$ domestica Borkh.): An assessment of factors affecting gene transfer efficiency during early transformation steps. Plant Cell Rpt. 13: $587-593$

Coetzer, C., D. Corsini, S. Love, J. Pavek, and N. Tumer. 2001. Control of enzymatic browning in potato (Solanum tuberosum L.) by sense and antisense RNA from tomato polyphenol oxidase. J. Agr. Food Chem. 49:652-657.

Dandekar, A.M., H.J. Fisk, G.H. McGranahan, S.L. Uratsu, H. Bains, C.A. Leslie, M. Tamura, M. Escobar, J. Labavitch, C. Grieve, T. Gradziel, P.V. Vail, S.J. Tebbets, S.H. Assa, R. Tao, W. Viss, J. Driver, D. James, A. Passey, and G. Teo. 2002. Different genes for different folks in tree crops: what works and what does not. HortScience $37: 281-286$

Dobranszki, J., K. Magyar-Tabori, E. Jambor-Benczur, and J. Lazanyi. 2000. New in vitro micrografting method for apple by sticking. Intl. J. Hort. Sci. 6:79-83.

Engelen, F.A. van, J.W. Molthoff, A. J. Conner, J.-P. Nap, A. Pereira, and W. J. Stiekema. 1995. pBINPLUS: An improved plant transformation vector based 
on pBIN19. Transgenic Res. 4:288-290.

Ewald, D. and U. Kretzschmar. 1996. The influence of micrografting in vitro on tissue culture behavior and vegetative propagation of old european larch trees. Plant Cell Tissue Organ Cult. 44:249-252.

Faggiol, F., L. Martino, and M. Barba. 1997. In vitro micrografting of Pyrus communis shoot tips. Adv. Hort. Sci. 11:25-29.

Ferree, D.C. and J.C. Schmid. 2001. An evaluation of 'Melrose' strains and selections. J. Amer. Pomol. Soc. 55:89-94.

Ferreira, S.A., K.Y. Pitz, R. Manshardt, F. Zee, F. Fitch, and D. Gonsalves. 2002. Virus coat protein transgenic papaya provides practical control of papaya ringspot virus in Hawaii. Plant Dis. 86:101-105.

Gittins, J.R., E.R. Hiles, T.K. Pellny, S. Biricolti, and D.J. James. 2001. The Brassica napus extA promoter: a novel alternative promoter to CaMV $35 \mathrm{~S}$ for directing transgene expression to young stem tissues and load bearing regions of transgenic apple trees (Malus pumila Mill.). Mol. Breed. 7: 51-62.

Guo, W.W. and X.X. Deng. 1998. Somatic hybrid plantlets regeneration between Citrus and its wild relative, Murraya paniculata via protoplast electrofusion. Plant Cell Rpt. 18:297-300.

Hadidi, A. 1995. In vitro micrografting: a technique to eliminate peach latent mosaic viroid from peach. Acta Hort. 386: 531-535.

Heuss, K., Q. Liu, F.A. Hammerschlag, and R.W. Hammond. 1999. A cRNA probe detects Prunus necrotic ringspot virus in three peach cultivars after micrografting and in peach shoots following long-term culture at $4{ }^{\circ} \mathrm{C}$. HortScience. 34:346-347.
Holefors, A.Z. T. Xue, L.H. Zhu, and M. Welander. 2000. The Arabidopsis phytochrome B gene influences growth of the apple rootstock M26. Plant Cell Rpt. 19: 1049-1056.

Huang, S.C. and D.F. Millikan. 1980. In vitro micrografting of apple shoot tips. HortScience. 15:741-743.

Ko, K.S., J.L. Norelli, J.P. Reynoird, H.S. Aldwinckle, and S.K. Brown. 2002. T4 lysozyme and attacin genes enhance resistance of transgenic 'Galaxy' apple against Erwinia amylovora. J. Amer. Soc. Hort. Sci. 127: 515-519.

Lane, W.D. 1978. Regeneration of apple plants from shoot meristem-tips. Plant Sci. Lett. 13:281-285.

Lane, W.D. 1992. Micropropagation of apple (Malus domestica Borkh.). Biotechnol. Agr. For. 18:231-241.

Lewandowski, M. and S. Zurawicz. 2000. Shortening the juvenile period in apple seedlings by grafting on P.22 dwarfing rootstock. J. Fruit Ornamental Plant Res. 8:33-37.

Monteuuis, O. 1995. Influence of the grafting technique on meristem micrografting of douglas-fir. New For. 10:267-273.

Mukhopadhyay, S., R. Jaishree, B.C. Sharma, G. Anita, R.K. Sengupta, P.S. Nath, J. Rai and A. Gurung. 1997. Micropropagation of darjeeling orange (Citrus reticulata Blanco) by shoot-tip grafting. J. Hort. Sci. 72:493-499.

Murashige, T. and F. Skoog. 1962. A revised medium for rapid growth and bioassays with tobacco tissue culture. Physiol. Plant. 15: 473-497.

Murata, M., M. Haruta, N. Murai, N. Tanikawa, M. Nishimura, S. Homma, and
Y. Itoh. 2000. Transgenic apple (Malus $\times$ domestica) shoot showing low browning potential. J. Agr. Food Chem. 48: 5243-5248.

Obeidy, A.A. and M.A.L. Smith. 1991. A versatile new tactic for fruit tree micrografting. HortTechnology. 1:91-95.

Perrin, Y., L. Lardet, F. Enjalric, and M.P. Carron. 1994. Rejuvenation of mature clones of Hevea brasiliensis (Mull. Arg.) by in vitro micrografting. Can. J. Plant Sci. 74:623-630.

Ponsonby, D.J. and S.H. Mantell. 1993. In vitro establishment of Picea pungens $\mathrm{f}$. glauca and P. sitchensis seedling rootstocks with an assessment of their suitability for micrografting with scions of various Picea species. J. Hort. Sci. 68:463-475.

Prakash, O., A. Sood, M. Sharma, and P.S. Ahuja. 1999. Grafting micropropagated tea (Camellia sinensis L. O. Kuntyze) shoots on tea seedlings - A new approach to tea propagation. Plant Cell Rpt. 18:883-888.

Thimmappaiah, G.T. Puthra and S.R. Anil. 2002. In vitro grafting of cashew (Anacardium occidentale L.). Sci. Hort. 92:177-182.

Yao, J.L., D. Cohen, R. van-den Brink, B. Morris, and R. van-den Brink. 1999. Assessment of expression and inheritance patterns of three transgenes with the aid of techniques for promoting rapid flowering of transgenic apple trees. Plant Cell Rpt. 18: 727-732.

Zhu, L.H, . M. Welander, O. Hellgren, and L.H. Zhu. 1999. Growth rates and biomass production of micropropagated apple plants of M.26 and Gravenstein on their own roots and in different micrografted combinations under nonlimiting and limiting nutrient conditions. J. Expt. Bot. 50: 1189-1198. 